\title{
Intermediate Grade Salivary Gland Mucoepidermoid Carcinoma
}

National Cancer Institute

\section{Source}

National Cancer Institute. Intermediate Grade Salivary Gland Mucoepidermoid

Carcinoma. NCI Thesaurus. Code C8017.

A salivary gland mucoepidermoid carcinoma with intermediate grade histopathologic features. 